or interview with stakeholders. Evaluation of the feasibility of the training will follow.

Discussion Various factors and interventions, the role of people with a chronic disease, and perceived value of work influence work participation irrespective of diagnosis. A training is developed to facilitate OHPs in the use of the evidence to optimise their support to people with a chronic disease.

\section{WORK DISABILITY PREVENTION: AN EXPANDING FRONTIER IN OCCUPATIONAL HEALTH}

'Johannes R Anema, ' William S Shaw. 'VU Medical Centre, Amsterdam, The Netherlands; ${ }^{2}$ UConn Health, Farmington, Connecticut, USA

\subsection{6/oemed-2018-ICOHabstracts. 1559}

Aim of special session The goal of this special session will be to provide an overview of emerging research in work disability prevention from a variety of national, disciplinary, and stakeholder perspectives. The session will not only address disability after work injuries, but also cancer, mental illness, and chronic medical conditions. Presenters will present research related to public and institutional policies, patient screening and assessment, job accommodation, employer and provider communication, and disability risk factors related to employee characteristics, medical diagnosis and treatment, and employer and family support.

${ }^{1}$ Angela GEM de Boer, ${ }^{2}$ Katherine Lippel, ${ }^{3}$ Cecile RL Boot, ${ }^{1}$ Karen Nieuwenhuijsen, ${ }^{4}$ Carolyn Dewa, ${ }^{5}$ Kelly Williams-Whitt

${ }^{1}$ Academic Medical Centre, Amsterdam, The Netherlands

${ }^{2}$ University of Ottawa, Ottawa, Ontario, Canada

${ }^{3}$ VU University Medical Centre, Amsterdam, The Netherlands

${ }^{4}$ University of California-Davis, Sacramento, California, USA

${ }^{5}$ University of Lethbridge, Calgary, Alberta, Canada

\section{9a WORK DISABILITY PREVENTION IN PEOPLE WITH A CANCER DIAGNOSIS}

A de Boer. Academic Medical Centre, University of Amsterdam, Department: Coronel Institute of Occupational Health, Amsterdam Public Health Research Institute, The Netherlands

\subsection{6/oemed-2018-ICOHabstracts. 1560}

In the last decades, work disability prevention in people with a cancer diagnosis has received growing attention worldwide. Approximately 14 million new cases of cancer are diagnosed globally each year with every 1 in 4 people ever diagnosed with cancer. The prevalence of cancer survivors within working age is expected to grow because of an ageing population, higher retirement age and continued improvements in treatment of many forms of cancer.

Almost half of all cancer survivors are younger than 65 years and of working age. Most cancer survivors will want to resume work after treatment but, regrettably, not all survivors are able to do so and unemployment is $40 \%$ higher than in people who never had cancer.

For this reason, innovative interventions that could mitigate the economic impact of surviving cancer and improve the quality of life of survivors are urgently required. In the past two decades, several interventions have been developed with approaches that were either psychological (e.g. counselling), physical (e.g. physical exercise, clinical interventions), vocational (e.g. job placement services, vocational rehabilitation), occupational (e.g. educating employers, implementation of work adjustments), and/or legislative (e.g. anti-discrimination acts) in their emphasis.

Multidisciplinary interventions have been proved to be most effective in return to work and work retention of cancer survivors. However, research has shown that collaboration between stakeholders can be challenging. Positive results can nevertheless be achieved when barriers for collaboration are removed.

There is a growing international awareness towards the work situation of cancer survivors. International networks uniting professionals, researchers, employers and stakeholders concentrate on disseminating research knowledge and best practice. Collaboration between countries on the development of evidence-based, validated interventions for work participation of cancer survivors to prevent unemployment will be highly beneficial.

\section{9b RETURN TO WORK AFTER WORK INJURY FOR PRECARIOUSLY EMPLOYED WORKERS}

${ }^{1} \mathrm{~K}$ Lippel, ${ }^{2} \mathrm{E}$ MacEachen. 'University of Ottawa, Ottawa, Ontario, Canada; ${ }^{2}$ University of Waterloo, Waterloo, Ontario, Canada

\subsection{6/oemed-2018-ICOHabstracts. 1561}

This paper presents results of a Canadian study looking at workers' compensation regulatory frameworks, designed to optimise return to work outcomes, as applied to precariously employed workers. Comparing frameworks in the two Canadian provinces of Québec and Ontario we find that in both provinces the quality and nature of incentives placed on employers and insurers to return workers to their maximum earning capacity is largely driven by their earnings at the time of injury, while the nature of the incentives placed on workers also varies depending on their earnings at the time of injury, but in different ways. Workers employed by temporary employment agencies are also disadvantaged because of the system design, regardless of their earnings. The disparity in incentives, particularly with regard to employers and insurers, leads to situations of systemic discrimination, whereby those whose work is undervalued at the time of injury, such as recent immigrants who are over-qualified for the positions they hold, receive minimalist support in return to work as compared to workers whose claims will be more costly for the system and the employer. Support is thus predicated on costs rather than potential employability or needs. Those in non-standard employment relationships are further undermined by the diffuse nature of responsibilities in return to work.

The study relies on classic legal methodology combined with interview data drawn from interviews undertaken in 2016 and 2017 with workers, employers, and key informants, a mixed methods approach which allows us to identify the specific rules in each of the two systems that favour or undermine adequate support in reducing work disability. 